\title{
Development of a College Life Adaptation Program for Freshman Student-Athletes
}

\author{
Sang-hyun Kwon* \\ Department of Physical Education, Yonsei University, Seoul, Korea
}

\begin{abstract}
[Purpose] The purpose of this study was to develop an effective college life adaptation program for freshman student-athletes. [Methods] A total of 160 student-athletes and 5 experts agreed to participate in this study. Four procedures were followed in this study: the needs assessment, the preliminary program development, and the application of the program. For the needs assessment, in-depth interviews were conducted, and the data were analyzed using an inductive reasoning process. [Results] The results of the needs investigation showed seven need factors and four interruption factors for college life adaptation. In addition, three need factors based on experience and seven interruption factors based on experience were found. The preliminary program was developed based on the needs assessment through the expert meeting, and the program consisted of four stages. Each stage consisted of three sessions, and each session contained a specific topic. The program was provided to nine freshman student-athletes in two months. As a result, the final program which consisted of four stages and thirteen sessions was developed after the reinforcement process based on evaluation of the preliminary program was conducted. [Conclusions] It is concluded that, the program is able to be expected to help them to understand their roles, have a better sense of responsibility and improve their self-esteem. Therefore, coaches and mental performance consultants should provide the college life adaptation program for freshman student-athletes to reduce their stress and have a better college life.
\end{abstract}

Key words: College life adaptation program, Freshman, student-athlete

\section{서 론}

사회로부터 법적인 보호를 받으며 부모와 교사가 나아갈 방향을 제시해주던 고등학생에서 전반적인 자신의 삶을 스 스로 결정하고 책임져야 하는 대학생이 된다는 것은 누구에 게나 어려운 일이다(Pritchard \& Willson, 2005). 이러한 변화의 시기에서 대학 신입생들은 혼란을 느끼게 되면서 대

논문 투고일 : 2021.04.02.

논문 수정일 : 2021.05.24.

게재 확정일 : 2021.06.09.

* 교신저자 : 권상현(kno1900@gmail.com)

* 이 논문은 2018년 한국연구재단의 지원을 받아 수행된 연구임

(NRF-2018S1A5B5A07073322).
학생활적응에 어려움을 경험한다(Hong, 2016). 대학생활 적응이란 개인이 대학의 구성원 및 환경과 상호작용하며 발 생하는 다양한 개인적·사회적 요구에 적절하게 대처하고 반 응하는 것이라 할 수 있다(Kim \& Kang, 2016). Downey (2005)는 대학생활적응 과정이 원활하지 못하면 신입생들 은 학교를 떠나 다시는 돌아오지 않을 것이라고 경고하며 대 학생활적응의 중요성을 강조하고 있다. 서구에서는 이 같은 점을 중요하게 다루며 1970년대부터 대학 신입생 관련 연 구를 적극적으로 수행해 왔다(Hong, 2016, Yu, 2011). 대 학 신입생 적응 교육에 관심을 가진 학자들은 신입생들에게 다양한 유형의(멘토링, 실습과 체험, 강의, 세미나) 교육을 제공하여 신입생 간의 유대감을 높이고, 교수와 학생 간의 
상호작용을 활성화하는 등 신입생들이 대학생활에 쉽게 적 응할 수 있도록 다양한 노력을 기울여왔다(Hong, 2016).

국내에서도 대학 신입생 교육의 중요성을 깨닫고 적극적 으로 연구를 진행하여 2009년부터 현재까지 대학 신입생 연구가 지속해서 증가하는 추세이다. Hong(2016)은 대학 신입생 연구에서 신입생들이 어떤 요인으로부터 심리적 어 려움을 겪는지 정확한 분석이 이루어져야 성공적으로 신입 생을 도울 수 있다고 강조하였다. 일반적인 대학 신입생의 대학생활적응의 주요 요소는 학업과 진로탐색(Hong, 2016; Kim \& Kang, 2016) 자아존중감 수준, 자기효능감 수준, 스트레스 수준, 인성(Kim, 2015; Song \& Jung, 2020; Yoo \& Kim, 2016) 등이 제시되고 있다. 국내 선행 연구를 살펴보면 간호학과(Kim, 2015; Park, 2014; Lee, \& Kim, 2018; Cho, 2014), 치위생과(Choi \& Lee, 2013), 유아교육과(Lee, 2018; Shu et al., 2012)등 다양 한 전공의 신입생을 대상으로 그들의 대학생활적응을 돕기 위해 프로그램을 개발하고 제공하였다. 그 결과, 대학 신입 생들의 적응을 돕는 것은 물론이며 더불어 자아존중감, 대 인관계 능력, 자기효능감 수준을 향상시켰다(Kim \& Chung, 2013; Kim, 2015; Kim et al., 2015; Lee, 2006; Lee \& Kim, 2018; Pyo \& Seok, 2010). 이처럼 대 학 신입생의 적응을 돕기 위한 프로그램은 성공적인 대학생 활의 출발을 돕는 교양 교육의 시작(Kang \& Kim, 2018)으 로 다양한 측면에서 중요성을 가지고 있다.

한편, 대학교에는 다양한 전공의 학생이 존재하는데 그중 학생 신분의 운동선수를 의미하는 학생선수(Studentathlete)는 학생(학업)과 운동선수(훈련과 시합) 두 가지 역 할을 모두 성공적으로 수행해야 하는 특수성을 가지고 있으 며, 일반적인 대학생이 경험하는 것과는 다른 유형의 독특한 스트레스 요소를 가지고 있다는 특징이 있다 (Papanikolaou et al., 2003; Pritchard \& Willson, 2005). 대학교 학생선수의 주된 스트레스는 학생과 운동선 수 두 가지 역할 사이에서 균형을 맞춰야 한다는 것이며, 그 로 인하여 신체적 피로, 학업 관리, 시간 관리, 부상관리, 대 인관계, 주전선수 여부 등의 다양한 스트레스가 추가로 발생 한다(Giacobbi et al., 2004; Petrie \& Stoever, 1997; Pritchard \& Willson, 2005; Stevens et al., 2013; Tracy \& Corlett, 1995). 이미 학생선수가 훈련으로 인한 육체적 피로와 불충분한 휴식시간으로 학업과 운동을 병행하는 것 에 대한 어려움 및 역할갈등을 경험하고 있으며, 신입생 시
기에 이로 인한 스트레스 수준이 특히 높다는 것이 선행연구 (Lee \& Ahn, 2014; Pritchard \& Willson, 2005; Shin et al., 2011)를 통해 밝혀졌다. 스트레스는 대학생활적응과 밀 접한 연관성이 있는 요인으로(Cho \& Chung, 2015; Song \& Jung, 2020) 이 같은 내용은 신입생 학생선수가 대학생활 적응에 어려움을 겪고 있으며 일반적인 대학 신입생과 차별 화된 도움이 필요함을 시사하고 있다(Choi et al., 2017; Pritchard \& Willson, 2005; Rasnack, 2011).

Shriberg와 Brodzinski(1984)에 따르면 미국에서는 1970년대부터 다양한 어려움을 경험하는 대학교 학생선수들 을 돕기 위해 학업 지도, 시간 관리, 강의계획에 초점을 맞춘 프로그램을 제공하였고, 1980년대에는 National Association of Academic Advisor, American College Personnel Association, National Association of Student Personnel Administrators 기관에서 학생선수를 위한 합동 워크숍을 개최하는 노력을 기울였다(Petitpas et al., 1995). 무엇보다도 고등학생에서 대학생으로 전환을 경 험하는 신입생 시기의 중요성이 강조되면서 신입생 학생선수 의 대학생활적응을 돕기 위한 목적으로 학업능력, 사회성, 대 인관계, 자기관리, 라이프스킬에 초점을 맞춘 'Freshman Athlete Scholastic Training Program(Harney, 1986)', 'Challenging Athletic Minds for Personal Success(NCAA, 2008)', 'Coorperative Evening Study Group Program(Dudley et al., 1997)', 'Psychoeducational group Program(Harris et al., 2003)', 'Life Skill Program(Rasnack, 2011)', 'Peer Mentoring Program(Meyer, 2020)', 'Resilience for the Rocky Road(Pierce et al., 2020)' 등의 다양한 프로그램을 개발하고 현장에 제공하였다. 위의 프로그램들은 각각 다양한 활동으로 구성되어 있으며, 신입생 학생선수가 학업에 특히 취약하다는 점을 고려하여 학업에 관련된 활동을 중심으로 시 간 관리, 음주 및 약물 교육, 성(sex)교육, 스트레스 관리, 심리 기술, 리더십, 의사소통, 목표설정 등의 내용을 포함하고 있다.

최근 우리 사회는 학생선수가 학업에 소홀하지 않도록 권장 하며 2016년부터 한국 대학 스포츠 총장 협의회(Korea University Sports Federation)에서 주최하는 대회에 일정 수준 이상의 학점을 획득하지 못한 선수는 대회 출전을 금하고 있다. 게다가 2016년에 큰 화제가 된 '정유라 사건' 이후 학생 선수에 관한 법이 한층 강화되어 신입생 학생선수의 전반적인 대학생활의 스트레스 수준이 향상되어 적응은 더욱 어려워지 
는 실정이다. 그러나 아쉽게도 국내에서는 공부하는 대학교 학 생선수의 경험에 관한 연구와(Kim et al., 2014) 대학에서 학 생선수의 삶을 위한 방향을 제시하는 연구(Lee \& Ahn, 2014) 그리고 학업을 돕는 프로그램(Choi \& Lee, 2020) 등이 진행 되었을 뿐 신입생 학생선수의 대학생활적응에 실질적인 도움 을 줄 수 있는 프로그램에 대한 고민은 이루어지지 않았다.

이 같은 상황에서 Choi et al.(2017)이 국내 신입생 학생 선수에 관심을 가지고 현장 개입 연구를 진행하여 신입생 학 생선수의 대학생활적응 요인과 방해요인 등을 제시하였다. 하지만 럭비와 아이스하키 종목의 팀 스포츠 선수만을 대상 으로 연구를 진행하였으며, 궁극적인 연구의 목적은 팀 빌딩 이었으므로 신입생 학생선수의 대학 생활 적응을 돕기 위한 프로그램으로서 독립성을 가지기에 충분하다고 할 수 없다. 이와 같은 점을 고려하면 현재 국내 신입생 학생선수의 대학 생활적응을 충분히 도울 수 있는 정보와 프로그램은 매우 부 족한 실정이라고 할 수 있으며, 아직도 많은 학생선수가 대학 교로 진학하는 과정에서 다양한 어려움에 노출되어 있음을 유추할 수 있다. 따라서 개인 스포츠 종목과 팀 스포츠 종목 의 신입생 학생선수 모두를 고려하고 현장의 요구가 충분히 반영된 대학생활적응프로그램을 개발해야 할 필요성이 있다 고 할 수 있다.

본 연구의 목적은 신입생 학생선수가 대학교에 진학하여 학업과 운동에 균형을 맞추며 대학생활에 효율적으로 적응할 수 있도록 돕는 대학생활적응 프로그램을 개발하는 것으로 본 연구의 목적을 달성하기 위한 연구문제는 다음과 같이 설정하 였다. 첫째, 신입생 학생선수의 대학 생활 적응에 필요한 것은 무엇인가? 둘째, 신입생 학생선수의 대학 생활 적응의 방해요 인은 무엇인가? 셋째, 신입생 학생선수의 대학 생활 적응을 돕기 위한 프로그램의 활동은 어떻게 구성되어야 하는가?

\section{연구방법}

\section{연구참여자}

본 연구의 목적을 달성하기 위하여 학생선수 160 명, 대학 교 운동부 지도자 3 명, 체육위원장 1 명, 스포츠심리학 교수 1 명이 연구에 참여하였다. 첫째, 총 9 개 종목(농구, 야구, 럭 비, 축구, 아이스하키, 스피드 스케이팅, 피겨 스케이팅, 테
니스, 골프)의 학생선수 160 명이 개방형 설문에 참여하였다. 그 중 자발적인 참여 의사를 보인 학생선수 10 명을 대상으로 심층면담을 진행하였다. 둘째, 지도자 3 명, 체육위원장 1 명, 스포츠심리학 교수 1 명 총 5명이 프로그램의 타당도 확보를 위해 전문가집단 회의에 참여하였다. 마지막으로 대학교 신 입생 학생선수 9명, 운동부 지도자 1명, 스포츠심리학 교수 1 명이 예비 프로그램에 참여하였다. 연구참여자의 세부적인 구성은 〈Table 1〉과 같다.

Table 1. Participant

\begin{tabular}{ccc}
\hline \hline Classification & Participant & N \\
\hline Open-ended question & Student-athlete & 160 \\
\hline In-depth interview & Student-athlete & 10 \\
\hline \multirow{2}{*}{ Expert group meeting } & $\begin{array}{c}\text { Head of sports committee } \\
\text { Sport psychology professor } \\
\text { College sports team coaches }\end{array}$ & 1 \\
& $\begin{array}{c}\text { College freshman } \\
\text { student-athletes }\end{array}$ & 9 \\
\hline Preliminary program & Sport psychology professor & 1 \\
& College sports team coach & 1 \\
\hline \hline
\end{tabular}

\section{조사도구}

\section{1) 개방형 질문지}

프로그램 개발 전 요구분석(needs analysis)을 위해 개방 형 질문지를 주(main) 도구로 활용하였다. 개방형 질문지는 선행연구(Choi et al., 2017; Hwang, 2017)를 바탕으로 전문가집단 회의를 거쳐 구성하였다. 개방형 질문지의 질문 은 '신입생 학생선수가 대학 생활(학업, 운동)에 쉽고 빠르게 적응하기 위해서 필요한 것을 모두 적어주세요.', '신입생 학 생선수가 대학 생활(학업, 운동)에 적응하는 것을 방해하는 요인을 모두 적어주세요.', '당신이 대학교 신입생이었던 때 를 생각해보세요. 당신은 신입생 때 학교생활과 운동부 생활 에 쉽고 빠르게 적응하였다고 생각하십니까? 만약 쉽고 빠르 게 적응하셨다면 어떤 점이 도움이 되었는지 자세하게 적어 주세요.', '만약 적응에 어려움이 있었다면 무엇 때문이었는 지 자세하게 적어주세요.'와 같이 구성하였다. 


\section{2) 심층면담}

개방형 설문 내용을 보다 심층적으로 이해하고 프로그램 을 개발하기 위하여 심층면담을 보조(sub)도구로 활용하였 다. 심층면담은 반 구조화된 면담방법을 활용하였으며, 개 방형 설문 답변 중 의미가 명확하지 않은 답변을 중심으로 1 인당 1 회 60 분 면담을 진행하였다. 면담은 개방형 설문에 참여하였던 학생선수 중 자발적 참여 의사를 밝힌 학생선수 를 대상으로 진행되었으며 학생선수가 원하는 시간과 장소 에서 진행하였다. 모든 면담내용은 연구참여자의 동의를 구 한 뒤 스마트 폰을 활용하여 녹음하였다.

\section{3) 예비 프로그램 평가지 및 경험보고서}

예비 프로그램의 평가를 위해 평가지와 경험보고서를 활 용하였다. 평가지와 경험보고서는 선행연구(Choi et al., 2017; Pierce et al., 2020; Kim et al., 2014)를 바탕으로 프로그램의 구성, 활동, 시간, 운영 등에 대하여 평가할 수 있도록 구성하였다. 또한, 경험보고서는 학생선수가 예비 프로그램에 참여하면서 느낀 생각과 감정에 대하여 자유롭 게 작성할 수 있도록 구성하였다.

\section{연구절차}

본 연구의 목적을 달성하기 위하여 스포츠심리학 현장에 서의 프로그램 개발 선행연구(Choi et al., 2017; Hwang, 2017)를 참고하여 다음과 같은 연구절차를 진행하였다.

첫째, 신입생 학생선수의 대학생활적응 프로그램의 목표 설정을 위해 학생선수 160 명을 대상으로 개방형 질문지 작 성을 요청하였으며, 그 중 자발적인 참여 의사를 밝힌 10명 을 대상으로 심층면담을 진행하였다. 이와 같은 요구분석은 자료수집을 통해 현장의 문제점 진단 및 해결책 탐색에 중요 한 과정으로 프로그램 개발에서 핵심이 되는 과정이며 (Royse et al., 2015), 대학 신입생 교육 프로그램에서의 그 중요성은 Hong(2016)의 연구를 통해 확인할 수 있다.

둘째, 요구분석(개방형 질문, 심층면담) 결과를 적극적으 로 반영한 전문가집단 회의를 진행하여 프로그램의 목표를 수립하고, 목표달성에 적합한 활동들을 수집 및 선정하는 과정을 통해 예비 프로그램을 구성하였다. 특히, 활동내용 은 관련 국내·외 선행연구에서 제시된 활동을 무분별하게 적용하지 않고 국내 대학교 신입생 학생선수에게 실질적인 도움이 될 수 있는 활동에 초점을 맞추어 선정하였다.
셋째, 위의 과정을 통해 구성된 예비 프로그램의 안면 타 당도를 확보하고 현장 적용 가능성을 검토하기 위하여 대학 교 신입생 학생선수 9명을 대상으로 두 달 동안 선호하는 시 간과 장소에서 예비검사(pilot-test)를 진행하였다. 마지막 으로 예비 프로그램이 모두 종료된 후 작성된 프로그램 평가 지와 경험보고서 그리고 전문가집단의 의견을 통합하여 프 로그램을 최종 수정·보완하는 과정을 거쳐 안면 타당도와 내용 타당도가 확보된 최종 프로그램을 완성하였다. 본 연 구의 연구절차는 〈Fig. 1 과 같다.

수집된 자료는 귀납적 범주분석 절차에 따라 영역별로 분 류하고 이후 주제별로 범주화하는 과정을 거쳤다. 수집된 모든 자료는 전사(transcribe)하였으며 전사된 자료는 코딩 작업을 통해 코딩영역을 분류하고 주제별로 묶어 하위범주 로 분류하였다. 특히, 코딩 과정에서 연구자의 주관적 해석 을 방지하기 위하여 동료검증(peer debriefing)을 진행하 여 확인을 거듭하였고 연구자 간 삼각검증(investigator triangulation)을 진행하였다.

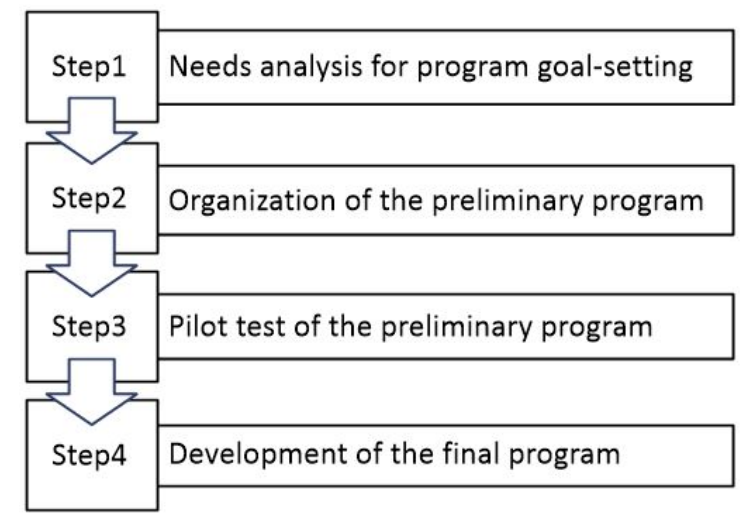

Fig. 1. Program development process

\section{연구결과}

\section{1단계: 프로그램 목표설정을 위한 요구분석 단계}

\section{1) 개방형 설문}

신입생 학생선수 대학 생활 적응프로그램의 목표설정을 위 
해 대학교 학생선수 160 명을 대상으로 개방형 질문지를 활용 하여 요구분석을 진행한 결과는 다음과 같다. 첫째, 신입생 학 생선수 대학 생활 적응에 필요한 요인은 긍정적 대인관계, 긍 정심리, 대학정보, 학업능력, 긍정적 환경, 학교지원, 효율적 시간 관리 총 7 개 요인으로 나타났다. 그중 긍정적 대인관계 가 $41.8 \%$ 로 가장 많은 비중을 차지하는 것으로 나타났으며 긍정적 심리(20.1\%), 대학정보(11.0\%), 학업능력(9.4\%), 긍 정적 환경(6.9\%), 학교지원(6.6\%), 효율적 시간 관리(4.1\%) 순으로 나타났다. 대학 생활 적응 필요요인의 세부적인 분석 결과는 〈Table 2〉와 같다.

둘째, 신입생 학생선수 대학 생활 방해요인은 환경변화, 부 정적 위계문화, 이중역할, 학업능력부족 총 4 개 요인으로 나 타났다. 그중 환경변화가 $33.3 \%$ 로 가장 많은 비중을 차지하 였고 부정적 위계문화(24\%), 이중역할(22.2\%), 학업능력 부
족(20.5\%) 순으로 나타났다. 대학 생활 적응 방해요인의 세부 적인 분석결과는 〈Table 3 〉과 같다.

셋째, 학생선수의 경험에 의한 요인을 확인하기 위한 질문 을 분석한 결과, 개방형 설문에 참여한 학생선수 중 85 명 (53.1\%)은 신입생 시절 어려움 없이 대학 생활에 적응한 것으 로 나타났으며, 긍정적 대인관계(73.6\%), 긍정심리(18.9\%), 기타 (7.5\%) 총 3개 요인으로 인해 어려움 없이 대학 생활에 적응 한 것으로 나타났다. 세부적인 분석결과는 〈Table 4>와같다. 넷 째, 개방형 설문에 참여한 학생선수 중 75명(46.9\%)은 대학 생 활 적응에 어려움을 경험한 것으로 나타났으며, 환경변화 (23.8\%), 부정적 위계문화(23\%), 학업능력 부족(13\%), 이중역 할(11.5\%), 대학정보 부족(10.7\%), 대인관계 부재(9\%), 부정 적 심리(9\%) 총 7개 방해요인으로 인해 적응에 어려움을 겪었 던 것으로 나타났다. 세부적인 분석결과는 〈Table 5〉와 같다.

Table 2. Need factors

\begin{tabular}{|c|c|c|c|}
\hline Raw-data & Lower order themes & $\begin{array}{l}\text { Higher order } \\
\text { themes }\end{array}$ & $\begin{array}{l}\text { Freq. } \\
(\mathrm{n}=318)\end{array}$ \\
\hline - Communicating frequently about academic matters & Relationship between juniors and seniors & \multirow{6}{*}{$\begin{array}{l}\text { Positive } \\
\text { interpersonal } \\
\text { relationship }\end{array}$} & 43 \\
\hline - Participating in freshman orientation, social drinking & Various types of social activities & & 39 \\
\hline - Recieving class information from general & Relationshin with general students & & 26 \\
\hline students when I am absent & & & 18 \\
\hline - Getting close to teammates in the same grade & Relationship with teammates in the same grade & & \multirow{2}{*}{7} \\
\hline - Communication with the coaching staff & Relationship with coaches and professors & & \\
\hline - Being diligent & Activeness & \multirow{4}{*}{$\begin{array}{c}\text { Positive } \\
\text { psychological state }\end{array}$} & 29 \\
\hline · Having hobbies & Psychological ventilation & & 20 \\
\hline - Showing good attitude & Sociability & & 11 \\
\hline - Tying to be confident & Confidence & & 4 \\
\hline - Understanding how to manage academic credit & Academic infrormation & \multirow{2}{*}{ College information } & 25 \\
\hline - Understanding school rules & General school information & & 10 \\
\hline - How to use power point & Report ability & \multirow{3}{*}{ Academic ability } & 19 \\
\hline - Studying skills to understand lectures properly & Understanding & & 9 \\
\hline - How to present properly & Presentation ability & & 2 \\
\hline - Proper amount of training time & Training environment & \multirow{2}{*}{$\begin{array}{c}\text { Positive } \\
\text { environment }\end{array}$} & 12 \\
\hline - Autonomous lifestyle & Life envirionment & & 10 \\
\hline - Mentor system & Mentor system & \multirow{2}{*}{ College support } & 12 \\
\hline - Increasing lectures only for student-athletes & Open lectures for student-athlete & & 9 \\
\hline - systematic schedule planning & Efficient time utilization & \multirow{2}{*}{ Time management } & 8 \\
\hline - Obvious time separation of training and lectures & Separation of training and lecture & & 5 \\
\hline
\end{tabular}


Table 3. Interruption factors

\begin{tabular}{|c|c|c|c|}
\hline Raw-data & Lower order themes & $\begin{array}{l}\text { Higher order } \\
\text { themes }\end{array}$ & $\begin{array}{c}\text { Freq. } \\
(\mathrm{n}=171)\end{array}$ \\
\hline - Alcohol abuse and clubbing & Social position & \multirow{3}{*}{$\begin{array}{c}\text { Environment } \\
\text { change }\end{array}$} & 35 \\
\hline Excessive amount of training time & Training environment & & 16 \\
\hline - Different life enviromment from high school & Life environment & & 6 \\
\hline - Bullying from older peers & Hierarchical interpersonal relationships & \multirow{3}{*}{$\begin{array}{l}\text { Negative } \\
\text { hierarchical } \\
\text { culture }\end{array}$} & 14 \\
\hline - Recieving punishment together from older peers & Negative custom & & 15 \\
\hline - Staying in the dormitory without a specific reason & Regulation of autonomy & & 12 \\
\hline - Overlapping lectures and training schedules & Schedule overlap & \multirow{2}{*}{ Dual roles } & 23 \\
\hline - Low level of concentration because of dual roles & Low level of concentration & & 15 \\
\hline - Difficulties with participating in group assignments & Report difficulty & \multirow{2}{*}{$\begin{array}{c}\text { Absence of } \\
\text { academic ability }\end{array}$} & 15 \\
\hline I do not understand anything because of the complexity of lectures & Lecture difficulty & & 20 \\
\hline
\end{tabular}

Table 4. Support factors based on experience

\begin{tabular}{|c|c|c|c|}
\hline Raw-data & Lower order themes & $\begin{array}{l}\text { Higher order } \\
\text { themes }\end{array}$ & $\begin{array}{l}\text { Freq. } \\
(\mathrm{n}=106)\end{array}$ \\
\hline - When I was a freshman, older peers academically supported me & Relationship between junior and senior & \multirow{5}{*}{$\begin{array}{l}\text { Positive } \\
\text { interpersonal } \\
\text { relationship }\end{array}$} & 43 \\
\hline $\begin{array}{l}\text { Having a friend as a mentor helped me focus more on } \\
\text { studying }\end{array}$ & Relationship with general students & & 11 \\
\hline $\begin{array}{l}\text { I was able to adapt easily to college life because of my same } \\
\text { grade teammates }\end{array}$ & Relationship with same grade teammate & & 11 \\
\hline $\begin{array}{l}\text { I went to membership training and I got to closer to } \\
\text { general students }\end{array}$ & Various types of social activities & & 11 \\
\hline $\begin{array}{l}\text { Professors tried to help me participate in class and train } \\
\text { successfully }\end{array}$ & Consideration of coaches & & 2 \\
\hline - Being open minded to learning new things & Activeness & \multirow{5}{*}{$\begin{array}{c}\text { Positive } \\
\text { psychological } \\
\text { state }\end{array}$} & 7 \\
\hline $\begin{array}{l}\text { I am energetic and talkative so I was able to get closer } \\
\text { to older peers }\end{array}$ & Sociability & & 6 \\
\hline I did not care what other people thought & Confidence & & 3 \\
\hline I am adaptable & Receptiveness & & 2 \\
\hline I tried to be focused on achieving my own goals & Concentration & & 2 \\
\hline - Good exercise environment & Positive training environment & \multirow{3}{*}{ etc. } & 4 \\
\hline Mentor and mentee & College support & & 2 \\
\hline $\begin{array}{l}\text { I had no problems because I am accustomed to managing my } \\
\text { studying and exercising time }\end{array}$ & Academic ability & & 2 \\
\hline
\end{tabular}


Table 5. Interruption factors based on experience

\begin{tabular}{|c|c|c|c|}
\hline Raw-data & Lower order themes & $\begin{array}{l}\text { Higher order } \\
\text { themes }\end{array}$ & $\begin{array}{c}\text { Freq. } \\
(\mathrm{n}=122)\end{array}$ \\
\hline - The dormitory life that I never experienced & Life environment & \multirow{3}{*}{$\begin{array}{l}\text { Environment } \\
\text { change }\end{array}$} & 15 \\
\hline $\begin{array}{l}\text { My health condition was bad because the amount } \\
\text { of training time was excessive }\end{array}$ & Training environment & & 11 \\
\hline $\begin{array}{l}\text { I often enjoyed drinking and did not do anything } \\
\text { the next day because of a hangover }\end{array}$ & Social position & & 3 \\
\hline - I was stressed because older peers were too strict & Hierarchical interpersonal relationship & \multirow{3}{*}{$\begin{array}{l}\text { Negative } \\
\text { hierarchical } \\
\text { culture }\end{array}$} & 17 \\
\hline - Oppressive environment & Regulation of autonomy & & 6 \\
\hline I was suffering from meaningless team customs & Negative custom & & 5 \\
\hline - Lecture contents were incomprehensible & Lecture difficulty & \multirow{2}{*}{$\begin{array}{l}\text { Absence of } \\
\text { academic } \\
\text { ability }\end{array}$} & 8 \\
\hline - Reports were stressful because I had never done it & Report difficulty & & 8 \\
\hline $\begin{array}{l}\text { I was not allowed to participate in a competition because } \\
\text { I did not get a high enough GPA. This was because of } \\
\text { an unavoidable schedule overlap }\end{array}$ & Schedule overlap & \multirow[t]{2}{*}{ Dual roles } & 9 \\
\hline - I had no time to take breaks in between class and training & Low level of concentration & & 5 \\
\hline - No one helped me manage academic credit & Academic information & \multirow{2}{*}{$\begin{array}{l}\text { Absence of } \\
\text { college } \\
\text { information }\end{array}$} & 9 \\
\hline - I did not know where lecture rooms were and how to pay my tuition & General school information & & 4 \\
\hline - There were no one that I could ask for advice & Relationship with general students & \multirow{2}{*}{$\begin{array}{l}\text { Absence of } \\
\text { interpersonal } \\
\text { relationship }\end{array}$} & 7 \\
\hline - I was not able to participate in school social events & Various types of social activities & & 4 \\
\hline - I felt I walked on eggshells around class peers & Nervous & \multirow{3}{*}{$\begin{array}{l}\text { Negative } \\
\text { psychological } \\
\text { state }\end{array}$} & 5 \\
\hline - Psychological pressure to become a main player in the team & Psychological pressure & & 4 \\
\hline - I was not able to approch someone because I am shy & Passive & & 2 \\
\hline
\end{tabular}

\section{2) 심층면담}

개방형 설문을 통해 긍정적 대인관계가 대학생활 적응을 위한 필요요인과 경험을 바탕으로 한 도움요인에서 가장 많 은 비중을 차지하고 있었다. 하지만 긍정적인 대인관계의 의 미가 불명확하다고 판단되어 명확한 의미를 확인하기 위하 여 심층면담을 진행하였다.

첫째, 대학생활적응을 위해 긍정적인 대인관계가 중요한 이유는 학교 및 학업에 대한 정보를 얻기 위한 목적이 있었음 을 확인할 수 있었다. 학생선수들은 신입생 시기에 훈련으로 인하여 입학 후 학교에서 주관하는 친목 활동에 참여하지 못 하는 경우가 많아 전반적인 학교정보를 얻기에 어려웠고, 이 같은 친목 활동에 참여하지 못하므로 일반학생과 가까워지 는 것도 쉬운 일은 아니다. 결과적으로 학교 및 학업 정보를 얻기 위해 주로 선배에게 의존하는 모습을 보이는데, 여기서 중요한 부분은 선배와의 관계 형성에 어려움을 느끼거나 아
는 선배가 없는 경우에는 대학생활적응에 어려움이 커질 수 있다는 것이다. 이와 같은 결과는 필요요인에서 나타난 대학 정보 및 학업능력 요인에 무게를 더할 수 있는 논리를 제공해 주었으며 세부적인 면담내용은 다음과 같다.

운동하다 보니까 학교모임에 참여를 안했는데 그러다 보니 일반 학 생들과 친해질 기회가 없었어요. 그래서 수업에 들어가면 나 혼자 친한 사람이 없다 보니 소외감을 느끼고 다가가는 것도 어려웠어요. 모르는 것이 있을 때도 동기한테 물어볼 수 있지만 졸업 관련 내용 은 선배들한테 물어봐야 한다고 생각하는데 아는 선배가 없다 보니 그런 것들이 힘들었던 것 같아요 (B선수).

저는 처음 입학했을 때 개인종목 선수여서 아는 사람이 없었어요. 그래서 학교랑 수업 관련 정보들을 쉽게 물어볼 사람이 없었어요. 저는 개인적으로 낮을 좀 많이 가리고 사람을 쉽게 사귀지 못하는 성격이어서 제가 먼저 말을 걸고 다가가는 것이 힘들어요. 그나마 
학교생활에 대하여 물어보기 위해서 접근을 했었어요. 그래서 굳이 내가 억지로 사람을 사귀어야 할 필요가 없도록 지도해 줄 수 있는 분이 계셨더라면 좋았을 것 같아요 (C선수).

저는 선배들이나 주변 친구들에게 학교 관련 문제를 많이 물어봤어 요. 선배들이 시간표 짜는 법을 알려 주었구요. 근데 선배들과의 관 계가 좋아야 이런 정보들을 쉽게 얻을 수 있어요. 만약 사이가 안좋 더라도 내가 필요로 하는 것들이기 때문에 용기를 내서 먼저 다가가 야 할 것 같아요 (D선수).

둘째, 개방형 설문에서 대학생활적응을 위해 동아리 활 동이 필요하다는 답변이 많이 나타났다. 동아리 활동은 친 목 활동 유형의 한 형태로 긍정적인 대인관계의 범주에 속할 수 있다. 그러나 동아리 활동을 제외한 다른 친목 활동은 학 교에서 주관하는 일회성 모임이었기에 다른 의미가 있을 것 으로 판단하여 동아리 활동에 대한 의미를 파악하기 위한 면 담을 진행하였다. 그 결과, 동아리 활동은 다른 친목 활동처 럼 학교 및 학업 정보를 얻기 위한 목적이 있기도 하였으나 심리적 환기의 목적이 더 강하다는 것을 알 수 있었다. 따라 서 동아리 활동과 관련된 내용은 긍정적 심리 요인으로 범주 화 하였으며, 성공적인 대학생활적응을 위해서는 운동과 학 업에 전념하는 것도 중요하지만 대학생활로 인해 발생한 스 트레스, 불안 등에 올바르게 대처하는 것이 중요하다는 것 을 알 수 있었다. 세부적인 면담내용은 다음과 같다.

저는 동아리 활동을 하고 싶었어요. 뭔가 그런 생각이 들더라구요 내가 하는 운동 말고 취미가 있나? 음악을 듣는다던가 다른 운동을 한다던가 생각해보니까 없더라구요. 저도 취미의 필요성을 못 느꼈 었는데 내가 하는 운동 말고 나 혼자서 스트레스를 해소할 수 있는 것이 있나? 만약 제가 운동에서 스트레스를 받으면 제 친구들도 다 같은 선수인데 개네랑 이야기하면 서로 너무 잘 알기 때문에 배부른 소리 한다느니 공감을 받기 힘들더라구요. 그러다 보니 고립되서 생 각을 하게 되더라구요. 오롯이 내가 좋아하는 것을 하는 시간이 필 요할 거 같아요 (A선수).

동아리 활동에서 느끼는 뿌듯함은 운동에서 느끼는 뿌듯함이랑 달 랐어요. 제가 운동할 때는 항상 혼자인거에요. 잘해도 혼자고 힘들 어도 혼자고 그런데 동아리 활동은 다함께 같이 무엇을 하다보니까 뿌듯한거같아요. 운동할 때는 잘하고 성취를 해도 떨어지면 안된다 는 스트레스? 기쁨은 잠시고 다음 시합도 잘해야 한다는 부담감이 있고 뭔가 뿌듯함을 느낄 수 있는 시간이 오래 가지 않았던 것 같아 요. 그런데 동아리 활동은 하나가 끝나면 계속 이어지는 것이 아니 다 보니 다음 걱정이생기는 것도 아니여서 뿌듯함이 오래 유지되었
던 것 같아요 (B선수).

\section{3) 요구분석 결과 통합 및 목표설정}

개방형 설문에서 나타난 필요요인(7개), 방해요인(4개), 경험을 바탕으로 한 도움요인(3개), 경험을 바탕으로 한 방 해요인(7개)과 심층면담 결과를 토대로 전문가집단 회의를 거쳐 프로그램의 목표를 설정하였다. 이때 각 요인이 차지 하고 있는 비중을 고려하고, 각 요인이 의미하는 바가 무엇 인지에 대하여 논하였다.

첫째, 대학생활적응 필요요인과 경험을 바탕으로 한 도 움요인에서 긍정적인 대인관계가 가장 많은 비중을 차지하 고 있었다. 이러한 대인관계 요인은 학교 및 학업에 대한 정 보를 얻기 위한 목적으로도 활용되고 있음이 심층면담을 통 해 확인되었다. 전문가집단은 이 같은 결과가 신입생 학생 선수가 학업을 중요한 요소로 인식하고 있지만 스스로 학업 을 관리할 수 없어 대인관계에 의지하고 있는 것으로 판단하 였다. 이에 신입생 학생선수의 대학생활적응을 돕기 위해서 는 학교정보 및 학업능력 요인에 무게를 두어야 한다는 것으 로 의견이 일치되어 프로그램의 첫 번째 목표는 신입생 학생 선수가 대인관계에 의지하지 않고 독립적으로 학업을 계획 및 관리하며 강의에 적극적으로 참여할 수 있는 기반을 구축 하는 것으로 설정하였다.

둘째, 긍정적 심리 요인이 필요요인과 경험을 바탕으로 한 도움요인에서 두 번째로 많은 비중을 차지하는 것으로 나 타났고, 부정적 심리 요인이 경험을 바탕으로 한 방해요인 에서 나타났다. 이러한 결과에 따라 전문가집단은 신입생 학생선수의 긍정적 심리가 대학생활에 충분히 반영될 수 있 어야 성공적으로 학업과 운동에 균형을 맞추며 효과적으로 적응할 수 있을 것으로 판단하여 신입생 학생선수가 스스로 스트레스를 관리하고 긍정적 심리를 가질 수 있도록 변화를 유도하는 것을 두 번째 목표로 설정하였다.

셋째, 대학생활적응 방해요인에서 환경변화 요인이 가장 많은 비중을 차지하고 있었으며, 그중 신분변화 요인에서 가장 많은 반응빈도가 나타났다. 이는 성인이 되면서 확대 된 사회적 권한이 유흥에 대한 관심으로 이어져 학업과 운동 에 소홀해지면서 자기관리 실패로 이어짐을 의미한다. 학생 선수와 일반 대학생의 음주를 비교한 연구에서 가장 과도한 음주 활동을 하는 대상이 신입생 학생선수라고 보고하였으 며, 이는 다양한 학업, 대인관계, 신체적 문제 및 위험과 연 결된 결과를 초래한다고 하였다(Doumas et al., 2007). 이 
러한 내용은 전문가집단 회의에서 신입생 학생선수가 성인 으로서 첫걸음을 내딛는 시기에 불미스러운 사건이나 범죄 에 노출되는 것을 예방해야 한다는 것으로 의견이 모아져서 학생선수가 신입생 시기에 인성과 자기관리 능력을 함양할 수 있도록 하는 것을 세 번째 목표로 설정하였다.

\section{2단계: 예비 프로그램 구성단계}

예비 프로그램 구성을 위해 목표설정 단계에서 수립된 세 가지 목표가 프로그램 전반에 걸쳐 달성될 수 있도록 선행연 구(Choi at al., 2017; Dudley at al., 1997; Giacobbi at al., 2004; Harris at al., 2003; Kim, 2015; Lee, 2006; Lee, 2018; Lee et al. 2009; Pierce et al., 2020; Rasnack, 2011)를 참고하여 적합한 활동을 수집하고 검토 하였다. 이후 전문가집단 회의를 통해 프로그램의 단계, 활 동내용, 진행시간 등에 대한 토의를 진행하고 예비 프로그램 을 구성하였다. 본 프로그램의 단계는 대학생활적응 프로그 램의 영역을 학업과 교양. 인성으로 구분한 $\operatorname{Kim}(2015)$ 의 연 구를 참고하여 학기 시작 전에 우선적으로 다루어져야 하는 자기탐색 및 학업관련 내용을 1 단계와 2 단계로 설정하였으 며, 학기 중에 진행될 수 있는 인성 및 자기관리 내용을 3단 계와 4단계로 설정하여 신입생 학생선수가 대학생활에 순차 적으로 적응할 수 있도록 하였다. 또한, 프로그램의 1 회기 시 간은 학생선수의 집중력을 고려하여 최대 90분을 넘지 않고 진행될 수 있도록 구성하였으며(Kwon et al., 2016), 프로 그램의 효과가 극대화될 수 있도록 교육(강의)과 실습을 조 화롭게 배치하였다. 이러한 과정을 통해 예비 프로그램은 총 4단계(준비단계, 대학생활적응 단계, 인성교육 단계, 마무리 단계) 12 회기로 구성되었다.

첫째, 1 단계는 '준비단계' 로 학생선수가 자신을 탐색하고 동기들과의 어색함을 부분적으로 해소하는 데에 목적이 있 다. 그리하여 '준비단계'는 '오리엔테이션'(1회기), '나와 동 료 알기'(2회기), 그리고 '학생선수에 대하여 생각해보기'(3 회기)로 구성하였다. '오리엔테이션'(1회기)에서는 본 프로 그램의 목적과 활동에 대하여 자세히 설명하는 시간과 프로 그램 진행 기간, 시간, 장소에 대하여 의견을 교환할 수 있도 록 하였다. '나와 동료 알기'( 2 회기)에서는 대학생활 기간 중 가장 오랜 기간 함께 해야 하는 동기와 긍정적인 관계를 맺을 수 있도록 'Egogram-test'와 동료를 인터뷰하고 소개하는 시간을 통해 자신과 동료를 이해하는 시간을 가질 수 있도록
하였다. 마지막으로 '학생선수에 대하여 생각해보기'(3회기) 에서는 프로그램의 본론에 들어가기 전 학생선수가 어떤 의 미이며 어떻게 받아들이고 생활해야 하는지 생각해보는 시 간을 가질 수 있도록 하였다.

둘째, 2 단계는 '대학생활적응 단계'로 효과적인 대학 생활 을 위해 필수적으로 알아야 할 대학정보를 습득하고 독립적인 학업계획 및 관리가 가능하도록 돕는 데에 목적이 있다. 이에 '대학생활적응 단계'는 '대학교 정보습득'(4회기), '학점관리 법'(5회기), ‘학업능력 기르기'(6회기)로 구성하였다. '대학교 정보습득'(4회기)에서는 강의실 위치 등을 포함한 전반적인 학교시설과 학교 홈페이지 및 온라인 캠퍼스를 활용하는 법을 익힐 수 있도록 하였다. 또한, 홈페이지를 통해 학과 및 교수 님을 소개하는 시간을 갖도록 하였다. '학점관리법' 5 회기)에 서는 강의계획서 확인 및 수강 신청법과 졸업까지 학점을 스 스로 관리할 수 있는 교육과 실습이 진행될 수 있도록 하였다. '학업능력 기르기'(6회기)에서는 과제물 진행법과 표절, 그리 고 발표하는 법에 대하여 교육이 진행될 수 있도록 하였다. 아 울러 과제물에서 활용되는 기본적인 워드 프로세서를 효율적 으로 다룰 수 있는 간단한 팁이 제공될 수 있도록 하였다.

셋째, 3단계는 '인성교육 단계'로 성인으로서 반드시 견 지해야 하는 책임의식과 준법의식 그리고 감정조절 능력을 발달시키고, 긍정적 대인관계 형성의 기초를 다져 인성과 자 기관리 능력을 함양하는 데에 목적이 있다. 이에 따라 '자기 관리'(7회기), '긍정적 대인관계'(8회기), 그리고 '감정 조절 하기'(9회기)로 구성하였다. '자기관리'(7회기)에서는 성인 으로 신분이 변화하면서 음주와 운전이 가능해지므로 술이 신체에 미치는 악영향에 대하여 교육하고 음주운전을 포함 한 음주 관련 사고 및 범죄에 대한 교육이 진행될 수 있도록 하였다. 이와 더불어 비교적 최근 스포츠계의 불법 스포츠도 박이 사회적인 화제가 되었기에 학생선수의 건강한 대학 생 활을 위해 불법 스포츠도박의 기준과 폐해에 대하여 교육이 진행될 수 있도록 하였다.

'긍정적 대인관계' (8회기)에서는 학생선수가 긍정적인 대 인관계를 형성하고 유지할 수 있도록 이해와 공감 및 배려와 존중에 대하여 교육하고 비폭력 의사소통법에 대하여 교육 과 실습이 진행될 수 있도록 하였다. 마지막으로 '감정 조절 하기'(9회기)에서는 자신의 다양한 감정에 대한 올바른 표현 법과 함께 스트레스 및 불안에 대하여 이해하고 대처하는 방 법에 대하여 교육이 진행될 수 있도록 하였다.

넷째, 4단계는 '마무리단계'로 그동안 신입생 학생선수들 
이 프로그램 참여를 통해 습득한 정보와 능력을 현장에 적용 하여 자기관리 할 수 있도록 하는 데에 목적이 있다. 이에 따 라 ‘목표 설정하기'(10회기), '시간 관리법'(11회기), '미래의 나에게 편지쓰기 및 종료'(12회기)로 구성하였다. '목표 설 정하기'(10회기)에서는 프로그램의 내용을 바탕으로 성공적 인 대학 생활을 할 수 있도록 올바른 목표설정법에 대한 교육 및 실습이 진행될 수 있도록 하였다. '시간 관리법'(11회기) 에서는 시간의 중요성을 교육하고, 목표설정과 연계된 일일
및 주간 계획서를 작성할 수 있도록 하였다. 마지막으로 '미 래의 나에게 편지쓰기 및 종료'(12회기)에서는 프로그램을 마치며 대학생활 동기부여를 위해 성공적인 자신의 미래를 상상해 볼 수 있도록 10년 후 나에게 편지쓰기 활동이 진행 될 수 있도록 하였다. 프로그램의 모든 활동이 종료된 이후 에는 프로그램 평가지와 경험보고서를 작성할 수 있도록 하 였다. 예비 프로그램의 전반적인 구성은 〈Table 6)과 같다.

Table 6. Contents of preliminary program

\begin{tabular}{|c|c|c|c|c|}
\hline Stage & Session & Activities & Purpose & Factors \\
\hline \multirow{3}{*}{ Preparation } & 1 & - Orientation & \multirow{3}{*}{$\begin{array}{l}\cdot \text { icebreaking } \\
\cdot \text { Realizing myself } \\
\cdot \text { Understanding teammates }\end{array}$} & \multirow{3}{*}{$\begin{array}{l}\text { Positive interpersonal } \\
\text { relationship } \\
\cdot \text { Dual roles }\end{array}$} \\
\hline & 2 & - Understanding myself and my teammates & & \\
\hline & 3 & - Thinking about what a student-athlete is & & \\
\hline \multirow{3}{*}{$\begin{array}{l}\text { College life } \\
\text { adaptation }\end{array}$} & 4 & - Acquisition of general college information & \multirow{3}{*}{$\begin{array}{l}\cdot \text { Acquiring essential } \\
\text { information for college life } \\
\text { - Independently managing } \\
\text { study }\end{array}$} & \multirow{3}{*}{$\begin{array}{l}\text { College information } \\
\cdot \text { Academic ability } \\
\cdot \text { Positive interpersonal } \\
\text { relationship }\end{array}$} \\
\hline & 5 & - Academic credit management & & \\
\hline & 6 & - Improvement of academic ability & & \\
\hline \multirow{3}{*}{$\begin{array}{l}\text { Character } \\
\text { education }\end{array}$} & 7 & Self-management as an adult & $\begin{array}{l}\cdot \text { Having responsibility as } \\
\text { an adult } \\
\cdot \text { Having law-abiding }\end{array}$ & \multirow{3}{*}{$\begin{array}{l}\cdot \text { Positive interpersonal } \\
\text { relationship } \\
\cdot \text { Positive psychological } \\
\text { state } \\
\cdot \text { Environment change } \\
\cdot \text { Negative hierarchical } \\
\text { culture }\end{array}$} \\
\hline & 8 & - Positive interpersonal relationship & mindset as a adult & \\
\hline & 9 & - Emotion management & $\begin{array}{l}\text { interpersonal relationships } \\
\text { - Learning to express } \\
\text { emotions correctly }\end{array}$ & \\
\hline \multirow{3}{*}{ Termination } & 10 & - Goal setting & \multirow{3}{*}{$\begin{array}{l}\cdot \text { Utilizing information } \\
\text { from the Program } \\
\cdot \text { Motivating my self }\end{array}$} & \multirow{3}{*}{$\begin{array}{l}\cdot \text { Dual roles } \\
\cdot \text { Time managrment } \\
\cdot \text { Positive psychological } \\
\text { state }\end{array}$} \\
\hline & 11 & - Time Management & & \\
\hline & 12 & $\begin{array}{l}\text { - Writing a letter to future my self } \\
\text { - Termination }\end{array}$ & & \\
\hline
\end{tabular}

\section{3단계: 예비검사 단계}

총 4단계 12회기로 구성된 예비 프로그램에는 신입생 학 생선수 9명과 전문가집단 2명이 두 달에 걸쳐 참여하였으며 본 프로그램이 모두 종료된 후 프로그램에 대한 평가를 진행 하였다. 평가지 분석결과, 본 프로그램은 신입생 학생선수의 대학생활적응을 돕는 데에 적합하며 기간과 시간도 적절하게 구성된 것으로 나타났다. 평가지의 분석결과는 〈Table 7〉과 같다. 이와 더불어 진행된 학생선수의 경험보고서에서는 조 금 더 새롭고 유용한 주제들을 더 많이 포함하면 좋을 것 같 다는 의견을 제외하고는 대부분 긍정적인 반응을 보였다. 또
한, 전문가집단 의견에서는 최근 사회적으로 성(sex)에 대한 올바른 인식과 주의가 요구되므로 7회기의 음주교육과 연계 하여 성교육이 추가되면 좋을 것 같다는 의견과 학생선수들이 학업에 대한 경험이 부족하기 때문에 충분한 시간을 활용하 여 학업능력을 향상시킬 수 있으면 좋겠다는 의견이 있었다.

\section{4단계: 최종 프로그램 개발단계}

최종 프로그램 개발을 위해 예비 프로그램 평가 결과와 경험보고서를 바탕으로 전문가집단 회의를 진행한 결과, 예 비 프로그램의 전반적인 내용이 신입생 학생선수 대학생활 
적응을 돕는 데에 적합하다고 판단되어 프로그램을 부분적 으로 수정 · 보완하는 것이 적절하다는 의견에 만장일치 하 였다. 최초 구성된 예비 프로그램에서 수정·보완된 사항은 다음과 같다.

첫째, 예비 프로그램에서 워드 프로세서 활용 팁에 대한 학습 은 6회기에 포함된 활동내용 중 하나였으며 학습시간이 비교적 짧았다. 이에 전문가집단은 충분한 시간을 활용하여 신입생 학생 선수의 학업능력을 향상시킬 수 있으면 더 효과적일 것이라는 의 견을 제시하여 6회기 전체를 '워드 프로세서 활용법'으로 수정하 는과정에서 표 만들기와차트 활용법 등의 세부적인 내용까지 다 룰 수 있도록 하였다. 이에 따라 기존의 나머지 활동들은 질 높은 과제물 완성에 도움이 되는 '정보 검색법' 활동을 추가하여 ‘학업
능력 향상 활동은 7회기로 재구성하였다.

둘째, 예비 프로그램의 ‘자기관리' 회기에는 성교육이 포 함되어 있지 않았으나 사회적으로 성에 대한 올바른 인식과 주의가 요구된다는 전문가집단의 의견을 반영하여 음주교 육과 연계한 성교육이 함께 이루어질 수 있도록 구성하였 다. 이와 같은 과정을 통해 최초 수립된 세 가지 목표를 달성 할 수 있는 4단계, 13 회기로 구성된 최종 프로그램이 개발 되었다. 본 프로그램은 학교 또는 팀 상황에 맞추어 탄력적 으로 운영할 수 있으나 학생선수의 원활한 수강신청과 학업 참여를 위해 1,2 단계는 학기 전에 진행되고 3, 4단계는 학 기 중에 진행되는 것이 효과적이다. 최종 개발된 프로그램 의 세부적인 내용은 〈Table 8>과 같다.

Table 7. Results of the evaluation of the preliminary program

\begin{tabular}{|c|c|c|c|c|c|c|}
\hline & Questions & $\begin{array}{l}\text { strongly } \\
\text { disagree }\end{array}$ & disagree & neutral & agree & $\begin{array}{c}\text { strongly } \\
\text { agree }\end{array}$ \\
\hline 1 & $\begin{array}{l}\text { This program is able to help freshman student-athletes adapt to } \\
\text { college life. }\end{array}$ & - & - & - & $\begin{array}{c}1 \\
(9.1 \%)\end{array}$ & $\begin{array}{c}10 \\
(90.9 \%)\end{array}$ \\
\hline 2 & The program leader properly managed the program. & - & - & $\begin{array}{c}1 \\
(9.1 \%)\end{array}$ & $\begin{array}{c}2 \\
(18.2 \%)\end{array}$ & $\begin{array}{c}8 \\
(72.7 \%) \\
\end{array}$ \\
\hline 3 & The duration of the program was appropriate. & - & - & - & $\begin{array}{c}4 \\
(36.4 \%) \\
\end{array}$ & $\begin{array}{c}7 \\
(63.6 \%) \\
\end{array}$ \\
\hline 4 & The program time per session was proper. & - & - & $\begin{array}{c}1 \\
(9.1 \%) \\
\end{array}$ & $\begin{array}{c}2 \\
(18.2 \%)\end{array}$ & $\begin{array}{c}8 \\
(72.7 \%) \\
\end{array}$ \\
\hline 5 & $\begin{array}{l}\text { The activities in the program are appropriate to support college } \\
\text { life adaptation for freshman student-athletes. }\end{array}$ & - & - & - & $(9.1 \%)$ & $\begin{array}{c}10 \\
(90.9 \%)\end{array}$ \\
\hline 6 & $\begin{array}{l}\text { I will participate in this type of program again if I have another } \\
\text { opportunity. }\end{array}$ & - & - & $\begin{array}{c}1 \\
(9.1 \%)\end{array}$ & - & $\begin{array}{c}10 \\
(90.9 \%)\end{array}$ \\
\hline 7 & I will recommend this program to freshman student-athletes. & - & - & - & - & $\begin{array}{c}11 \\
(100 \%)\end{array}$ \\
\hline
\end{tabular}

Table 8. Final college life adaptation program

\begin{tabular}{|c|c|c|c|c|}
\hline Stage & Session & Activities & Time & References \\
\hline \multirow{3}{*}{ Preparation } & 1 & $\begin{array}{l}\text { Orientation } \\
\cdot \text { Explaining the program }\end{array}$ & $60 \mathrm{mins}$ & \multirow{3}{*}{$\begin{array}{c}\text { Choi et al.(2017) } \\
\text { Harris et al.(2003) } \\
\text { Lee(2006) } \\
\text { Pierce et al.(2020) } \\
\text { Rasnack(2011) }\end{array}$} \\
\hline & 2 & $\begin{array}{l}\text { Understanding myself and my teammates } \\
\cdot \text { Egogram-test } \\
\cdot \text { Interviewing and presenting my teammates }\end{array}$ & $75 \mathrm{mins}$ & \\
\hline & 3 & $\begin{array}{l}\text { Thinking about what a student-athlete is } \\
\text { - Thinking about what my roles are as a college student and as an athlete } \\
\text { - Thinking about good things and difficulties as a student-athlete }\end{array}$ & $75 \mathrm{mins}$ & \\
\hline
\end{tabular}


Table 8(continue). Final college life adaptation program

\begin{tabular}{|c|c|c|c|c|}
\hline Stage & Session & Activities & Time & References \\
\hline \multirow{3}{*}{$\begin{array}{l}\text { College life } \\
\text { adaptation }\end{array}$} & 4 & $\begin{array}{l}\text { Acquisition of general college information } \\
\text { - Acquiring college facilities } \\
\text { - How to utilize the online campus } \\
\text { - Introducing professors }\end{array}$ & $75 \mathrm{mins}$ & \multirow{3}{*}{$\begin{array}{l}\text { Choi at al.(2017) } \\
\text { Dudley et al.(1997) } \\
\text { Harris et al.(2003) } \\
\text { Rasnack(2011) }\end{array}$} \\
\hline & 5 & $\begin{array}{l}\text { Academic credit management } \\
\text { - Learning what a syllabus is and how to check it } \\
\text { - Learning how to sign up for lectures and manage academic credits } \\
\text { How to utilize word processors } \\
\text { - How to utilize Power-point } \\
\text { - How to utilize Hangul word processor }\end{array}$ & 90mins & \\
\hline & 7 & $\begin{array}{l}\text { Improvement of academic ability } \\
\text { - Understanding basic rules of lectures } \\
\text { - Learning how to create reports and avoid plagiarism } \\
\text { - Learning how to search academic information } \\
\text { - Learning how to present in class }\end{array}$ & 90mins & \\
\hline $\begin{array}{l}\text { Character } \\
\text { education }\end{array}$ & 10 & $\begin{array}{l}\text { Self-management as an adult } \\
\text { - Alcohol, Sex and Sports Gambling Education } \\
\text { - Negative effects of alcohol on the human body } \\
\text { - Understanding STD and sex crimes } \\
\text { - Understanding what illegal sports gambling is } \\
\text { Positive interpersonal relationships } \\
\text { - Acquiring nonviolent communication } \\
\text { - Understanding basic etiquette of the department and team } \\
\text { Emotion management } \\
\text { - Learning how to express my emotions correctly } \\
\text { - Understanding what stress and anxiety are } \\
\text { - Learning how to cope stress and anxiety }\end{array}$ & 90mins & $\begin{array}{l}\text { Choi at al.(2017) } \\
\text { Giacobbi et al.(2004) } \\
\text { Harris et al.(2003) } \\
\text { Kim(2015) } \\
\text { Lee(2006) } \\
\text { Lee et al.(2009) } \\
\text { Pierce et al.(2020) } \\
\text { Rasnack(2011) }\end{array}$ \\
\hline \multirow{3}{*}{ Termination } & 11 & $\begin{array}{l}\text { Goal setting } \\
\cdot \text { Understanding how to set up goals } \\
\text { - Setting my own goals }\end{array}$ & 90mins & \multirow{3}{*}{$\begin{array}{l}\text { Harris et al.(2003) } \\
\text { Lee(2006) } \\
\text { Lee(2018) } \\
\text { Rasnack(2011) }\end{array}$} \\
\hline & 12 & $\begin{array}{l}\text { Time Management } \\
\text { - Understanding the importance of time } \\
\text {. Planning daily and weekly schedules based on goals }\end{array}$ & 90mins & \\
\hline & 13 & $\begin{array}{l}\text { Writing a letter to future myself / Termination } \\
\text { - Imagining and Writing a letter to my self } 10 \text { years from now } \\
\text {. Evaluating the program and writing self-reports }\end{array}$ & $60 \mathrm{mins}$ & \\
\hline
\end{tabular}

\section{논 의}

본 연구의 목적은 신입생 학생선수를 위한 대학생활적응 프로그램을 개발하는 것으로 본 연구에서 나타난 결과를 논 의하면 다음과 같다.
첫째, 본 연구에서는 신입생 학생선수의 대학생활적응에 관한 요구를 보다 정확하게 파악하기 위해 선행연구(Choi et al., 2017)에서 진행한 개방형 설문과 함께 심층면담을 추가로 진행하였으며, 경험을 바탕으로 한 도움요인과 방해 요인을 추가 분석하였다. 본 연구의 요구분석을 통해 총 7 개 
의 필요요인 및 경험을 바탕으로 한 3 개의 도움요인과 4 개의 방해요인 및 경험을 바탕으로 한 7개의 방해요인이 나타났 다. 이는 선행연구(Chartrand \& Lent, 1987; Choi et al., 2017; Giacobbi et al., 2004; Harney et al., 1986; Harris et al., 2004; Hong, 2016; Kim \& Kang, 2016; Rasnack, 2011)를 부분적으로 지지하는 결과이다.

본 연구에서는 선행연구(Choi et al., 2017; Pinkerton et al., 1989; Rasnack, 2011)와 같이 대인관계 요인이 신 입생 학생선수의 대학생활적응 주요 요소로 나타났다. 본 연 구에서 긍정적인 대인관계는 대학생활 적응 과정에서 전반 적인 학교생활 및 학업에 대한 정보와 도움을 쉽게 얻기 위한 목적으로 활용되는 것이 확인되었다. 그러나 안타깝게도 현 실적으로 팀 내 선배를 제외한 다양한 대인관계 형성에 어려 움이 존재하고 교수 또는 지도자는 도움을 요청하기에 어려 운 존재(Cho \& Lee, 1996)이므로 결국 선배에게 의존하게 되는 경우가 많다. 따라서 이미 알고 지내던 선배가 같은 대 학교에 진학해 있거나 선배와의 관계가 긍정적일 경우 대학 생활적응이 비교적 쉽지만 그렇지 않으면 다양한 어려움을 마주하게 된다.

이는 국외 선행연구(Dudley et al., 1997; NCAA, 1998; Rasnack, 2011)에서 긍정적인 관계 형성 및 관계개선에 초 점을 맞추어 제시된 대인관계 요인과 차별화된 결과라고 할 수 있다. 또한, 선·후배 간의 의사소통과 관계를 중요한 요소 로 제시하며 본 연구를 지지하는 Choi et al.(2018)의 연구 에서도 확인하지 못하였던 부분으로 선행연구를 보완하는 의미 있는 결과라 할 수 있다. 정리하자면 국내 신입생 학생 선수의 성공적인 대학생활적응을 위해서 선행연구에서 제시 하였던 것과 같이 학업적인 부분이 중요한 역할을 하는데, 그동안 이를 대인관계에 의지해왔으므로 신입생 학생선수들 은 대인관계를 대학생활적응을 위해 중요한 요소로 인식하 고 있었던 것이라 할 수 있다. 따라서 본 연구에서 긍정적 대 인관계는 관계 개선 측면과 학업적인 측면에서 다루어졌다 는 특징을 가지고 있다.

둘째, 요구분석 필요요인에서 학교정보와 학업능력 요인 이 나타났고, 방해요인에서 학업능력 부족, 학교정보 부족, 이중역할 요인이 나타났다. 위에 나열된 요인을 통해 신입생 학생선수 대학생활적응에 학업이 중요한 요소임을 재확인할 수 있었다. 아울러 학업에 대한 준비가 부족한 상태에서 대 학에 진학한다는 것과 훈련 또는 시합과 강의시간의 중복으 로 강의를 놓치게 되면서 학업적인 어려움이 극대화되고 있
음을 알 수 있었다. 이러한 문제는 비단 국내 학생선수만의 문제는 아니며 국외에서도 오래전부터 발생하고 있는 문제 로(Simons et al.1999) 쉽게 해결될 수 있는 문제가 아님을 알 수 있다.

따라서 본 연구에서는 신입생 학생선수의 학점을 직접 높 이기 위한 공부법(study skill)에 초점을 맞춘 선행연구 (Dudley et al., 1997; Harney et al., 1986; Harris et al., 2003; Rasnack, 2011)와 다르게 학생선수의 학업에 대한 자율성을 높이는 것에 목표를 두고 접근하였다. 그리하여 4 회기 7회기 활동에서 수업계획서 확인법, 수강신청법, 학점 관리법, 발표법, 과제 해결법, 워드프로세서 활용법 등 다양 한 부분을 교육하고 실습할 수 있도록 구성하였다. 이는 아 직 학업에 대한 경험과 정보가 적은 학생들에게 거부감을 주 지 않으면서 흥미를 유발할 수 있는 효과적인 접근법이라고 생각한다. 그렇지만 이와 같은 방법도 학업적인 문제를 완벽 하게 해결할 수 없으므로 추후 본 프로그램과 함께 학생선수 를 위한 강의 개설 및 체계적인 멘토 시스템(Choi \& Lee, 2020; Zevallos \& Washburn, 2014) 구축과 같은 학교의 노력이 더해진다면 신입생 학생선수가 학업과 훈련에서 적 절한 균형을 찾는 것은 더 이상 어려운 문제가 아닐 것이다.

셋째, 본 연구에서 신입생 학생선수가 청소년에서 성인이 되면서 겪는 환경변화로 인해 혼란을 경험하고 빈번한 유흥 에 노출되어 자기관리에 실패하는 것으로 나타났다. 성인으 로 신분이 변화하는 과정에서 발생하는 혼란은 자아존중감 수준에 부정적인 영향을 미치게 되는데(Loeb \& Magee, 1992), 자아존중감은 공격성과 부적인 관계를 가지고 있다 (Pyon \& Kang, 2002). 그러므로 이 시기에 자아존중감 관 리에 실패하게 되면 학업과 훈련에 대한 자기관리 실패는 물 론이며, 더 나아가 신입생 학생선수의 잦은 음주문화 (Doumas et al., 2007)가 여러 범죄로 연결될 위험성이 있 다. 따라서 본 프로그램에서는 인성교육 단계를 통해 이 같은 문제점을 예방할 수 있도록 하였으며 선행연구(Choi et al., 2017; Harris et al., 2003; Rasnack, 2011)에서도 성교육, 음주교육, 약물교육 등과 같은 교육을 프로그램에 포함하여 신입생 시기에 인성 및 자기관리 교육의 중요성을 강조하고 있다.

넷째, 본 연구에서 개발된 프로그램은 예비검사를 통해 현장에 적용이 가능하다는 결과를 얻었다. 프로그램의 전반 적인 구성은 선행연구 고찰, 요구분석, 전문가집단 회의, 예 비검사 과정을 모두 거쳐 타당도를 확보하였기에 현장 적용 
시 긍정적인 효과를 기대해볼 수 있다. 그러나 학생선수는 훈련과 학업의 이중역할로 인하여 시간 관리에 어려움을 가 지고 있으므로 프로그램이 진행되는 동안 훈련시간이 적절 하게 조절되지 않는다면 학생선수에게 프로그램은 또 다른 하나의 스트레스 요인으로 작용할 가능성이 있다. Choi et al.(2017)은 팀 빌딩 프로그램 적용 시 선수들이 학업 및 훈 련 그리고 프로그램에 모두 참여하는 상황이 지속 되자 피로 누적으로 선수들이 진행자에게 휴식을 요구하는 일이 발생 하였다고 보고하였다. 따라서 운영자는 프로그램이 진행되 는 기간에는 프로그램 참여가 최우선이 될 수 있도록 각 운동 부 지도자와 협조하여 학생들이 안정된 심리상태에서 프로 그램에 참여할 수 있도록 도와야겠다.

\section{결론 및 제언}

본 연구는 신입생 학생선수를 위한 대학생활적응 프로 그램을 개발하는 것에 목적이 있었으며 결론은 다음과 같 다. 신입생 학생선수 대학 생활 적응을 위한 요인으로 7 개 의 필요요인과 4 개의 방해요인이 나타났으며 학생선수 경 험에서는 3 개의 도움요인과 7 개의 방해요인이 나타났다. 이 같은 과정을 통해 총 4단계 12 회기의 예비 프로그램을 구성하고 예비검사를 진행하여 최종적으로 총 4단계 13 회기의 신입생 학생선수를 위한 대학 생활 적응프로그램 을 개발하였다.

본 연구결과를 바탕으로 후속연구에 대하여 제안하면 다음과 같다. 첫째, 후속연구에서는 본 연구에서 개발된 프로그램을 현장에 적용하여 대학생활적응을 확인하는 것과 더불어 자존감, 행복감 등의 다양한 프로그램 효과를 검증할 필요가 있다. 둘째, 본 연구에서 개발된 프로그램 은 약 2 3달간 활용할 수 있다. 그러나 신입생 적응프로 그램은 한 학기에 걸쳐 진행되는 것이 더욱 효과적이므로 후속 연구에서는 본 프로그램이 종료된 후에 추가로 참여 가능한 보조 프로그램(예: 진로교육)을 개발하여 활용할 필요성이 있다. 셋째, 신입생 학생선수의 대학생활적응 수 준을 올바르게 측정하기 위해서는 신뢰도와 타당도가 확 보된 측정도구가 필요하다. 하지만 일반 대학생을 위한 척 도만 개발되어(Kim \& Kang, 2016) 활용되고 있으므로 후속연구에서는 신입생 학생선수를 위한 측정도구를 개 발하여 활용해야 할 것이다.

\section{참고문헌}

Chartrand, J. M., \& Lent, R. W. (1987). Sports counseling: Enhancing the development of the student athlete. Journal of counseling \& development, 66(4), 164-167.

Cho, H. K., \& Chung, S. K. (2015). Relationship among college life stress, alienation and college adjustment: focused on transferred and non-transferred nursing students. Journal of the Korean Data Analysis Society, 17(5), 2779-2793.

Cho, I. Y. (2014). The relationship of career identity, major satisfaction and college adaptation of nursing freshmen. Journal of the Korea Academialindustrial Cooperation Society, 15(5), 2937-2945.

Cho, Y. H., \& Lee, S. H.(1996). The relationship between communication styles and organizational effectiveness in business sport centers. Korean Journal of Physical Education, 35(2), 2395-2403.

Choi, H. J., \& Lee, M. S. (2013). The associations of social support and ego-resilience on college adjustment among dental hygiene freshmen. The Korean Public Health Association, 39(2), 129-138.

Choi, S. H., \& Lee, B. C. (2020). Making student-athletes to study. Korean Journal of Sports Scirnce, 29(2), 719-730.

Choi, J. S., Kwon, S. H., \& Hwang, J. W. (2017). Development and application of a team building program focused on adaptation to college life and new team of freshmen student-athletes. Korean Journal of Sport Science, 28(4), 1046-1062.

Doumas, D. M., Turrisi, R., Coll, K. M., \& Haralson, K. (2007). High risk drinking in college athletes and nonathletes across the academic year. Journal of College Counseling, 10(2), 163-174.

Downey, V. P. (2005). An exploration of the adjustment processes of freshmen student-athletes and non-athlete students. Unpublished Doctoral Dissertation, West Virginia University.

Dudley, B. S., Johnson, D. W., \& Johnson, R. T. (1997). Using cooperative learning to enhance the academic and social experiences of freshman student athletes. The Journal of Social Psychology, 137(4), 449-459.

Giacobbi, P. R., Lynn, T. K., Wetherington, J. M., Jenkins, J., 
Bodendorf, M., \& Langley, B. (2004). Stress and coping during the transition to university for first-year female athletes. The Sport Psychologist, 18(1), 1-20.

Harney, M. K., Brigham, T. A., \& Sanders, M. (1986). Design and systematic evaluation of the Freshman Athlete Scholastic Training program. Journal of Counseling Psychology, 33(4), 454-461.

Harris, H. L., Altekruse, M. K., \& Engels, D. W. (2003). Helping freshman student athletes adjust to college life using psychoeducational groups. Journal for Specialists in Group Work, 28(1), 64-81.

Hong, S. Y. (2016). Need analysis on education for supporting first-year students' adjustment to college. The Journal of Educational Research, 14(1), 271-295.

Hwang, S. H. (2017). Development of a team building program to improve the cohesion of the youth soccer team. The Korean Journal of Physical Education, 56(5), 419-433.

Kang, S. B., \& Kim, K. H. (2018). A study on the effectiveness of preliminary college program. Korean Journal of General Education, 12(1), 57-72.

Kim, D. W., Kim, S. Y., \& Kim, D. H. (2014). A narrative inquiry on the university experiences of student-athletes to study. Korean Journal of Physical Eduaction, 53(3), 329-340.

Kim, J. M., Shin, J. T., \& Park, Y. S. (2014). The effect of happiness improvement program development on psychological and physiological variables of collegiate badminton players. Korean Journal of Sport Science, 25(3), 434-449.

Kim, K. H., \& Kang, S. B. (2016). Development and validation of the college life adjustment scale for university freshmen. Korean Journal of General Education, 10(3), 253-293.

Kim, S. M., \& Chung, K. E. (2013). Effects of mentoring program on adjustment to college and academic self-efficacy in university freshman. Korea Institute of Youth Facility \& Environment, 11(4), 201-210.

Kim, Y. H. (2015). The effects of college life adaptation program on nursing students college life adaptation and nursing professional attitude. Journal of the Korea Academia-Industrial Cooperation Society, 16(12), 8948-8956.

Kim, Y. J., Kim, Y. Y., \& Lee, S. M. (2015). The relationships among self-esteem, satisfaction with major, career identity and university life adjustment of university students in the department of children's English education. Journal of Digital Convergence, 13(9), 39-47.

Kwon, S. H., Choi, J. S., \& Yook, D. W. (2016). Development of a communication training program and application for a college ice hockey team. Korean Journal of Sport Science, 27(4), 941-956.

Lee, K. H., \& Kim, M. A. (2018). Effects of a rational emotive behavior therapy counseling program on self-efficacy and adjustment to college life for nursing freshmen. The Journal of Korean Academic Society of Nursing Education, 24(4), 443-452.

Lee, S. H. (2006). Influences of mentoring program on adjustment to college life and self-esteem in nursing college students. Journal of Korean Academy of Nursing Administration, 12(2), 247-254.

Lee, S. H., Jeong, H. S., Lee, D. W., Park, K. H., Yun, Z. Y., \& Park, J. J. (2009). Influence of anxiety, depression and stress on adjustment to college in freshmen of a university. Korean Journal of Family Medicine, 30(10), 796-804.

Lee, S. N. (2018). The effect of college adjustment program for freshman majoring early childhood education on pre-service early childhood teacher's academic self-efficacy, major satisfaction, and career adaptability. The Journal of Korea Early Childhood Education, 25(3), 107-130.

Lee, T. K., \& Ahn, Y. K. (2014). Directions for lives of student athletes in university. Sports Science, 31(2), 111-122.

Lee, Y. A. (2006). A study on the developing character education program for prevention from dropouts. The Journal of East West Science, 9(1), 95-104.

Loeb, R. C., \& Magee, P. M. (1992). Changes in Attitudes and Self-Perceptions during the First Two Years of College. Journal of College Student Development, 33(4), 348-355.

Meyer, A. D. (2020). Initial Findings on the Implementation of a Peer Mentoring Program (PMP) for Freshman Student-Athletes. Unpublished Doctoral Dissertation, Morehead State University.

National Collegiate Athletic Association. (2008). NCAA CHAMPS/Life Skills Program 2008-09.

Papanikolaou, Z., Nikolaidis, D., Patsiaouras, A., \& Alexopoulos, P. (2003). Commentary: The freshman experience: High stress - low grades. Athletic Insight: The Online Journal of Sport Psychology, 5 
Park, H. T. (2014). A study on the effect of emotional intelligence on adjustment to college life in first year nursing college students. Journal of the Korea Academia-Industrial Cooperation Society, 15(3), 1576-1583.

Petitpas, A. J., Buntrock, C. L., Van Raalte, J. L., \& Brewer, B. W. (1995). Counseling athletes: A new specialty in counselor education. Counselor Education and Supervision, 34(3), 212-219.

Petrie, T. A., \& Stoever, S. (1997). Academic and nonacademic predictors of female student-athletes' academic performance. Journal of College Student Development, 38(6), 599-608.

Pierce, S., Martin, E., Rossetto, K., \& O’Neil, L. (2020). Resilience for the Rocky Road: Lessons Learned from an Educational Program for First Year Collegiate Student-Athletes. Journal of Sport Psychology in Action, 1-14.

Pinkerton, R. S., Hinz, L. D., \& Barrow, J. C. (1989). The college student-athlete: Psychological considerations and interventions. Journal of American College Health, 37(5), 218-226.

Pritchard, M., \& Wilson, G. (2005). Comparing sources of stress in college student athletes and non-athletes. Athletic Insight: The Online Journal of Sports Psychology, 5(1), 1-8.

Pyo, C. W., \& Seok, E. J. (2010). Effect of self-growth program on the freshman of early childhood education department of self-esteem and personal relations capability. The Korean Society for Study on Welfare of Early Childhood Education and Educare, 14(4), 119-139.

Pyon, B. K., \& Kang, S. K. (2002). A study of adolescents' self-esteem and hostility. Korean Journal of Youth Studies, 9(3), 269-291.

Rasnack, C. N. (2011). The effects of a life skills program on the social and academic performance of freshman student-athletes. Unpublished Master Dissertation, Western Wachington University.

Royse, D., Thyer, B. A., \& Padgett, D. K. (2015). Program evaluation: An introduction to an evidence-based approach. Cengage Learning.

Shin, C. H., Kim, D. J., \& Oh, J. K. (2011). College athletes' perception on athlete study support program. Korean Association of Sport Pedagogy, 18(3), 39-54.

Shriberg, A., \& Brodzinski, F. R. (1984). Rethinking services for college athlete. New directions for student-athletes in division I revenue producing sports. Sociology of Sport Journal, 9, 48-59.

Simons, H. D., Van Rheenen, D., \& Covington, M. V. (1999). Academic motivation and the student athlete. Journal of College Student Development, 40, 151-162.

Song, J. H., Jung, E. Y. (2020). Fators affecting adaptation to university life of first-year students. Journal of the Korean society for Wellness, 15(1), 173-183.

Stevens, R. E., Loudon, D. L., Yow, D. A., Bowden, W. W., \& Humphrey, J. H. (2013). Stress in college athletics: Causes, consequences, coping. Routledge.

Suh, H. J., Won, K. S., \& Lim, J. H. (2012). The effect of the mentoring program for freshmen of department of early childhood education on adapting to their major. The Institute of Humanities Soonchunhyang University, 31(1), 177-205.

Tracey, J., \& Corlett, J. (1995). The transition experience of first-year university track and field student athletes. Journal of the First-Year Experience \& Students in Transition, $7(2), 81-102$

Yoo, K. H., \& Kim, J. K. (2016). A review study on adjustment of college freshmen for suggesting adaptation program. The Journal of the Korea Contents Association, 16(8), 580-591.

Yu, S. A. (2011). An analysis of first-year experience in U.S. as an alternative for college curriculum reform. Korean Journal of Comparative Education, 21(5), 29-57.

Zevallos, A. L., \& Washburn, M. (2014). Creating a culture of student success: The SEEK scholars peer mentoring program. About Campus, 18(6), 25-29. 


\title{
신입생 학생선수를 위한 대학 생활 적응프로그램 개발
}

\author{
권상현 \\ 연세대학교 강사
}

[목적] 본 연구의 목적은 신입생 학생선수가 대학 생활에 효과적으로 적응하도록 돕는 프로그램을 개발하 고 신입생 학생선수를 위한 프로그램의 기초자료를 제공하는 것이다. [방법] 본 연구의 목적을 달성하기 위하 여 학생선수 160 명과 전문가집단 5명이 참여하였다. 대학 생활 적응프로그램 개발을 위해 개방형 설문 및 심 층면담을 통한 요구분석, 예비 프로그램 구성, 예비검사를 진행하였다. [결과] 첫째, 요구분석에서 7개의 필요 요인과 4 개의 방해요인이 나타났다. 이와 더불어 학생선수들의 경험을 바탕으로 한 3 개의 지원요인과 7 개의 방해요인이 나타났다. 요구분석 결과를 바탕으로 전문가집단 회의를 진행하여 총 4단계, 12 회기로 구성된 예 비 프로그램을 구성하였다. 이후 9명의 신입생 학생선수와 2 명의 전문가가 두 달 동안 예비 프로그램에 참여 하였다. 예비 프로그램이 종료된 후 평가를 진행하였으며, 평가 결과를 바탕으로 프로그램을 수정·보완하였다. 그 결과, 최종적으로 총 4단계, 13 회기의 신입생 학생선수 대학 생활 적응프로그램이 개발되었다. [결론] 본 연구에서 개발된 프로그램은 신입생 학생선수가 자신의 역할과 책임에 대하여 올바르게 인식하고 긍정적인 대인관계 형성 및 자아존중감 향상을 기대해 볼 수 있다. 그러므로 대학교 관계자 및 지도자 그리고 스포츠심 리상담사는 신입생 학생선수들의 성공적인 대학 생활을 위해 본 프로그램을 현장에 적극적으로 제공할 필요가 있다.

주요어: 대학 생활 적응프로그램. 신입생, 학생선수 